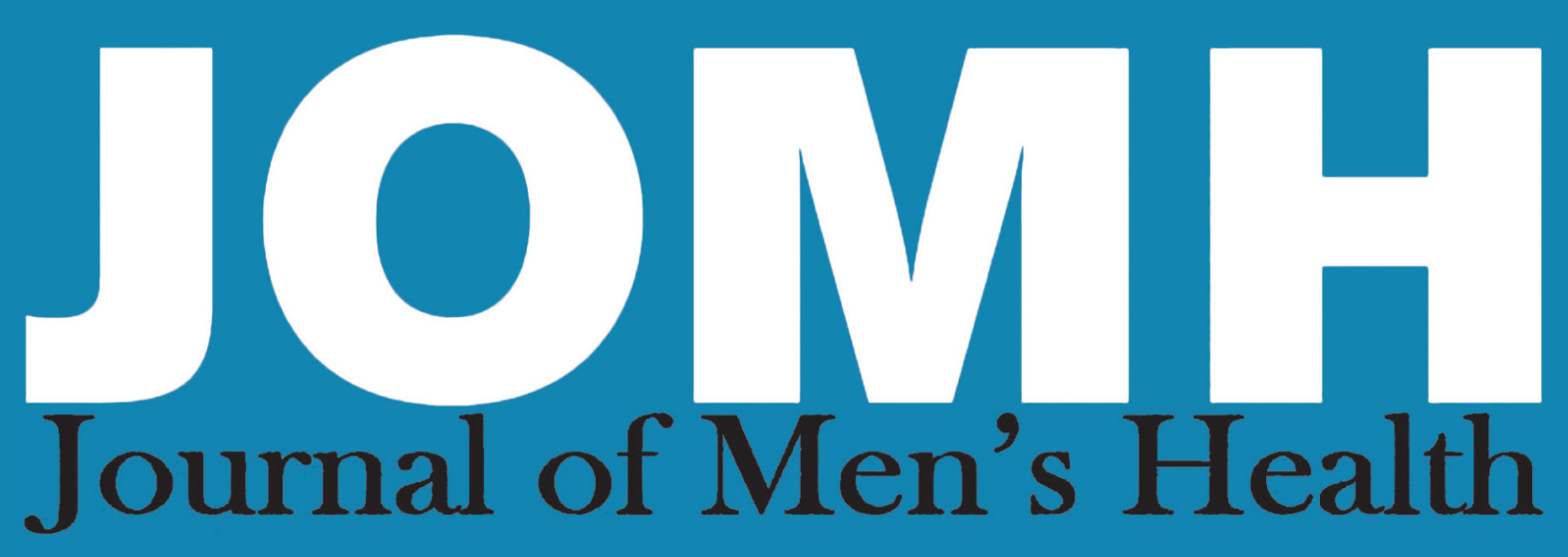

Original Article

DOI: 10.31083/jomh.v16i4.252

\title{
TESTOSTERONE AND SELF-PERCEIVED MASCULINITY IN AN AUSTRALIAN COHORT OF COMMUNITY-DWELLING MEN
}

Andrew Peel, MBBS ${ }^{1}$, Sean Martin, BSc, $\mathrm{PhD}^{1}$, Andrew Vincent, $\mathrm{PhD}^{1}$, Deborah Turnbull, $\mathrm{PhD}^{1}$, Xinjun Wang, $\mathrm{PhD}^{2}$, Margaret McGee, $\mathrm{MPH}^{1}$, David Jesudason, $\mathrm{PhD}^{2}$, Suzanne Chambers, $\mathrm{PhD}^{3}$, Gary Wittert, MD ${ }^{1 *}$

${ }^{1}$ Freemasons Centre for Male Health and Wellbeing, The University of Adelaide and South Australian Health and Medical Research Institute, Adelaide, South Australia, Australia

${ }^{2}$ The Queen Elizabeth Hospital, Woodville, South Australia, Australia

${ }^{3}$ Faculty of Health, University of Technology, Sydney, New South Wales, Australia

*Corresponding Author: Professor Gary Wittert: gary.wittert@adelaide.edu.au

Submitted: 08 April 2020. Accepted: 10 September 2020. Published: 05 October 2020.

\section{ABSTRACT}

\section{Background and objective}

Traditional masculinity is characterised by traits of independence, toughness, assertiveness, competitiveness and physical competence. Multiple factors modulate the expression of masculinity, including age, social class, ethnicity and occupation. While there is a perception that physiological testosterone concentration impacts self-perceived masculinity in men, there are limited supporting data. This study aimed to examine the relationship between testosterone concentration and self-perceived masculinity as measured by the Masculinity in Chronic Disease Inventory (MCD-I), controlling for health-related and biopsychosocial factors in community-dwelling, middle-aged to elderly men.

\section{Materials and methods}

Participants were drawn from a longitudinally followed cohort $(\mathrm{N}=1195)$ of men participating in the Florey Adelaide Male Aging Study based in Adelaide, Australia. A final sample of 460 (mean age 65.15, standard deviation 9.72) men consisted of those with serum testosterone concentrations measured at wave one (2002-2005) and wave two (2007-2010), and who, in 2017, completed the Masculinity in Chronic Disease Inventory questionnaire and provided information related to demographics, medical conditions, health and lifestyle behaviours.

Adjusted multivariable regression analyses were undertaken to determine the relationship between serum testosterone concentration at wave 2 and MCD-1 total masculinity score and sub-scores. Given the 
temporal difference between the testosterone concentration assessment and MCD-1 completion, a further analysis was performed including participants with a stable serum testosterone concentration over a 5-year period.

\section{Results}

There was no association between serum testosterone concentration and MCD-1 total masculinity score ( $p=0.54)$ or sub-scores $(p=0.12-0.85)$. There was also no association between testosterone concentration and total masculinity score in men with stable serum testosterone over time $(p=0.35)$. Testosterone concentration was associated with serum sex-hormone-binding globulin (SHBG) concentration $(p<0.001)$, age $(p<0.001)$, waist circumference $(p<0.001)$ and a history of diabetes $(p=0.021)$. Total masculinity score was lower in men without a partner (widowed $p<0.013$, separated/divorced $p<0.019$ ), a history of anxiety $(p=0.036)$ and moderate $(p=0.05)$ to severe erectile dysfunction $(p<0.001)$.

\section{Conclusion}

This study provides evidence against the perception that physiological testosterone concentration impacts self-perceived masculinity. Rather, in middle-aged to older men, self-perceived masculinity is abrogated by psychosocial factors and chronic physical disorders.

Keywords: testosterone; masculinity; MCD-I; partner; erectile dysfunction

\section{INTRODUCTION}

"Traditional" masculinity tends to be characterised by traits such as independence, toughness, assertiveness, emotional control, competitiveness and physical competence. ${ }^{1-3}$ The extent to which these traits are inherently biological or socially constructed is a matter of ongoing debate. ${ }^{4}$ The expression of masculinity is modulated by multiple factors, including age, social class, ethnicity, occupation, geographical location and disability. ${ }^{1,5-7}$ One potential biological modulating factor is the sex steroid testosterone, which is essential for the development and maintenance of male physical characteristics. It is not known whether physiological testosterone has an impact on men's self-perceived masculinity.

Artificial elevation of serum testosterone concentration in men has been associated with certain features of masculinity, such as increased sexual desire, ${ }^{8,9}$ self-perceived dominance, ${ }^{10}$ dominant behaviour $^{11}$ and physical strength. ${ }^{12}$ Conversely, testosterone deficiency is associated with lack of physical strength, and more passive behaviours. ${ }^{13,14}$ While often perceived to be the case, it is unclear, however, as to whether the concentration of physiological testosterone is associated with self-perceived identification with, or adherence to, the traditional traits of masculinity. There is only a limited number of studies examining this relationship, ${ }^{15,16}$ and of those, only one study was undertaken in the relevant cohort (males) using salivary testosterone concentration, finding no association with masculinity. ${ }^{16}$

Furthermore, chronic health conditions, such as obesity and persistent depression, are associated with reductions in serum testosterone concentrations. ${ }^{17,18}$ It is unknown as to whether these chronic diseases impact self-perceived masculinity, and if so whether it is mediated by changes in serum testosterone concentration. Whilst there are a number of different instruments to assess self-perceived masculinity, $3,19,20$ the Masculinity in Chronic Disease Inventory (MCD-1) was designed to specifically evaluate masculinity in the context of chronic disease..$^{21,22}$

In this study, we have interrogated the relationship between serum testosterone concentration and self-perceived masculinity, as measured by MCD-1, and the presence of chronic disease, and the 
interaction between them in a cohort of urban, community-dwelling, middle-aged to elderly Australian men.

\section{METHODS}

\section{Participants and Study Outline}

Participants were drawn from the Florey Adelaide Male Aging Study (FAMAS) cohort, described in detail elsewhere. ${ }^{23}$ Briefly, FAMAS comprises randomly selected, community-dwelling, male residents in the Northern and Western Statistical Local Areas of Adelaide, Australia, aged at least 35 years at recruitment. ${ }^{23}$ Men included in the primary analysis cohort were those with complete serum testosterone concentration data from wave 1 (2002-2007) and wave 2 (2007-2010), as well as self-perceived masculinity and socio-demographic and lifestyle data, collected via postal survey conducted between 2016 and $2017(n=460$, Figure 1).

Ethics approval was granted for the FAMAS cohort study by the Human Research Ethics Committee for the Royal Adelaide Hospital, and informed consent was obtained from all participants.

\section{The MCD-I Questionnaire}

The MCD-I is a 22-item, participant-completed questionnaire that assesses self-perceived masculinity (identification with traditional masculine traits) across six sub-domains: action approach, emotional self-reliance, physical strength, family responsibilities, optimistic capacity and sexuality. The MCD-I has been validated for use in men with prostate cancer $^{2}$ and chronic disease. ${ }^{22}$ The MCD-I provides a total masculinity score $(\max 110)$, which is the cumulative sum of each sub-domain score.

\section{Serum Testosterone Concentration}

During clinic visits for waves 1 and 2, venous blood samples were drawn between 8:00 AM and 11:00 AM after a 12 hour overnight fast and $20 \mathrm{~min}$ in a sitting position. Samples were immediately placed on ice, then centrifuged, fractionated and serum was stored at $-80^{\circ} \mathrm{C}$ before testosterone concentration was measured using an API-5000 triple quadrupole mass spectrometer (Applied Biosystems/ MDS SCIEX, Toronto, Ontario, Canada). Samples from the two waves were assayed concurrently. The inter-assay coefficients of variation were: $10.1 \%$ at $0.43 \mathrm{nmol} / \mathrm{L}, 11.1 \%$ at $1.66 \mathrm{nmol} / \mathrm{L}$ and $4 \%$ at 8.17 $\mathrm{nmol} / \mathrm{L}^{17}$

\section{Covariate Data}

Validated, self-reported questionnaires were administered at the time of the MCD-I to collect covariate data, including socio-demographic characteristics (education, income, marital status); behavioural and lifestyle characteristics (smoking, employment); and history of being diagnosed by a doctor as having any of the following conditions: depression (yes/no), anxiety (yes/no), angina (yes/ no), diabetes (yes/no), prostate cancer (yes/no) and erectile dysfunction (nil to mild, moderate, severe). ${ }^{23}$ Waist circumference (WC) was measured to the nearest $0.1 \mathrm{~cm}$ using an inelastic tape maintained in a horizontal plane midway between the bottom of the ribs and the top of the iliac crest, and read from the mid-axillary line, with the participant standing comfortably with weight distribution evenly on both feet.

\section{Statistical Analyses}

Descriptive analyses were used to describe the analysis cohort characteristics at the time of administering the MCD-I questionnaire. The generalisability of the analysis cohort to those excluded from the trial at the time of admission into the FAMAS trial was examined through $\chi 2$-tests and MannWhitney $U$ tests to compare the baseline demographic and chronic disease measures to the initial FAMAS cohort.

Unadjusted and covariate adjusted, multivariable, linear and robust regression analyses were undertaken to examine the association between serum testosterone concentration at the FAMAS 2 time point (2007-2010) to total MCD-1 masculinity 


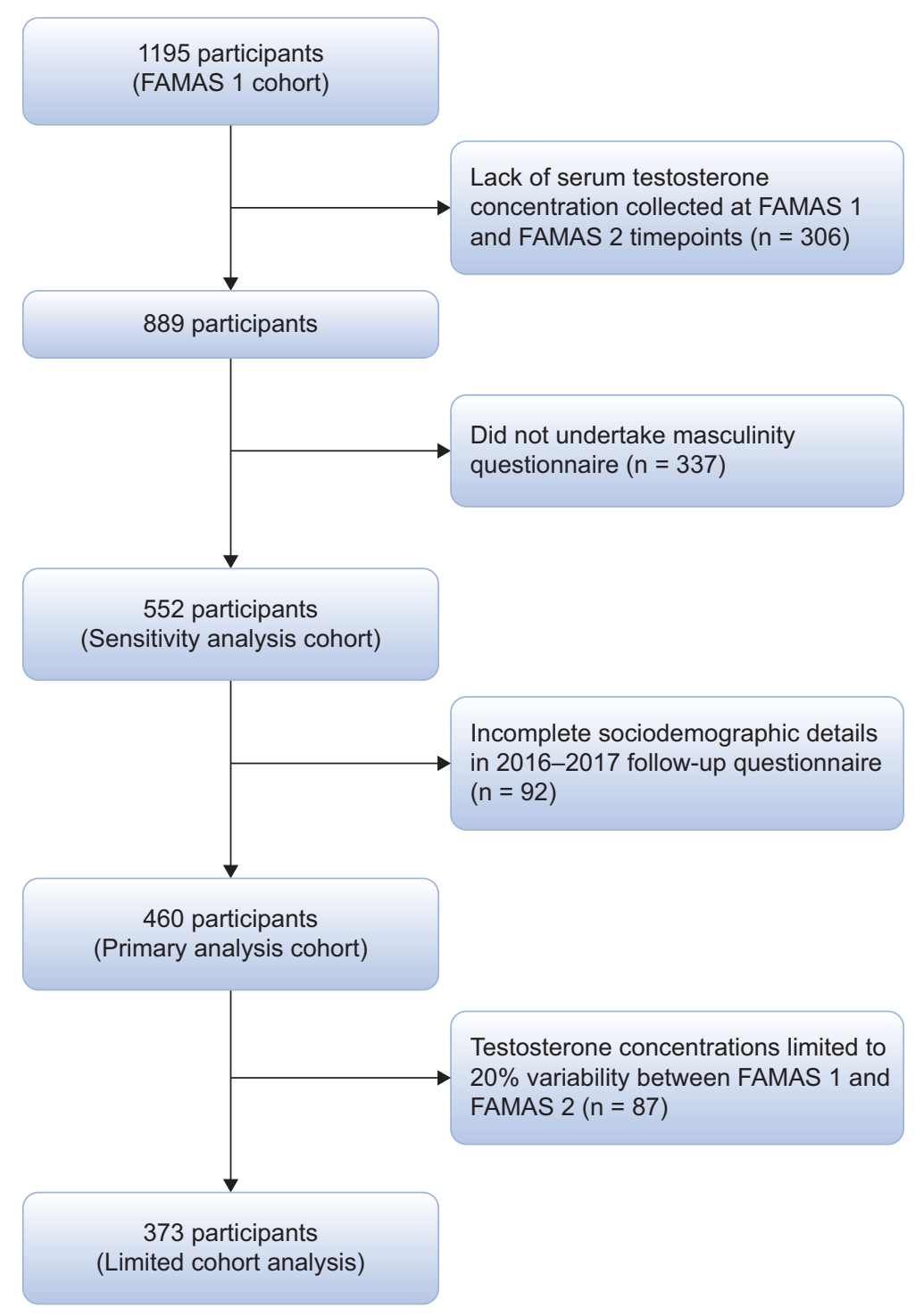

FIGURE 1 Consort diagram of FAMAS trial. Outlines the application of exclusion criteria to produce the primary analysis cohort. It simultaneously also shows process by which the sensitivity analysis cohort and limited cohort analysis were developed through relaxing and adding further exclusion criteria respectively.

score (2016-2017), and between serum testosterone concentration and each of the six sub-domain scores. Serum testosterone and sex-hormone-binding globulin (SHBG) were log-transformed prior to analysis.

Two additional analyses were performed to assess the association of testosterone concentration with the self-perceived masculinity score. First, given the temporal difference between testosterone concentration measurements and MCD-I completion, a multivariable regression analysis was performed using data only from participants with minimal variation in serum testosterone concentration between FAMAS 1 and FAMAS 2 waves $(<20 \%$ variation, $n=373$, - limited cohort analysis). This is based on the premise of these participants being most likely to have ongoing static serum testosterone concentrations, and 
as such, their FAMAS 2 testosterone concentrations are more likely to reflect testosterone concentration at the time of the MCD-I questionnaire completion, thereby limiting the impact of time.

Second, a sensitivity analysis was undertaken whereby the analysis was repeated on an extended cohort of participants $(\mathrm{n}=552)$, incorporating the primary analysis cohort and an additional 92 participants who had missing covariate data. Missing data were incorporated through naïve (mode) imputation. The only caveat to this was the erectile dysfunction data. These were the most common missing data, and it was assumed that imputation with the mode value (nil -mild erectile dysfunction) may yield false-negative results. As such, the data were imputed to an additional data value, "did not answer", for the erectile dysfunction question.

All analyses were conducted in $\mathrm{R}$ version 3.4.1. All $p$ values were two-sided and $p$ values $<0.05$ were considered significant.

\section{RESULTS}

\section{Descriptive Analyses}

At the time of administering the MCD-I questionnaire, most of the cohort were non-smokers $(91 \%)$, married (83\%) and had no history of diabetes $(86 \%)$, depression $(94 \%)$ or anxiety $(94 \%)$. The differences between the analysis cohort and those not meeting the inclusion criteria at the time of admission are shown in Supplementary Table 1. In summary, there were many differences including: younger age (53 vs 56 years old), lower rates of smoking (19\% vs $25 \%$ ), lower rates of diabetes $[12 \%$ vs $19 \%$, greater proportion of married men ( $87 \%$ vs $78 \%)$ ], smaller proportion of lower income earners $<\$ 40,000(35 \%$ vs $52 \%)$, greater proportion of full employment $(61 \%$ vs $30 \%$ ), lower rates of erectile dysfunction and lower rates of prostate cancer ( $1 \%$ vs $4 \%$ ).

By the time of MCD-I completion, more participants had retired (50\%) when compared to the time of FAMAS 1 (20\%), and the rate of moderate-to-severe erectile dysfunction had increased ( $50 \%$ vs $22 \%$ ).

\section{Testosterone and Total Self-Perceived Masculinity} [ $\beta$, (95\% Confidence Intervals) $p$ Value]

In unadjusted analysis, there was no association between the serum testosterone concentration and the total self-perceived masculinity score $(p=0.78)$ (Table 2). In covariate adjusted analysis, there was also no association between the serum testosterone concentration and the total self-perceived masculinity score ( $p=0.54$, robust regression $p=0.38)$ (Table 2). Also, there was no association between the serum testosterone concentration and any of the six MCD-I sub-domain scores (Supplementary Table 2).

In the limited cohort analysis with minimal variation in the serum testosterone concentration between FAMAS 1 and FAMAS 2, there was no association between the serum testosterone concentration and the total self-perceived masculinity score $(p=0.35)$ (Supplementary Table 3). With the incorporation of the additional 92 participants with missing covariate data in the sensitivity analysis, no association between the serum testosterone concentration and the total self-perceived masculinity score was detected ( $p=0.86$ ) (Supplementary Table 4).

\section{Covariate Data and Self-Perceived Masculinity [ $\beta$, (95\% Confidence Intervals) p Value]}

After adjusting for covariates, the total self-perceived masculinity score was negatively associated with the absence of a long-term partner [widowed: -9.63, (-16.37 -2.89), 0.005; separated/divorced: $-5.24,(-9.41-1.06), 0.01]$, anxiety [-5.24, $(-11.27$ $-0.17), 0.04]$, and severe erectile dysfunction $[-8.12$, $(-11.78-4.45),<0.001]$ (Table 2).

Middle income was the only covariate positive associated with the action approach sub-domain $(p=0.02)$, and being a smoker was associated with higher emotional self-reliance sub-domain scores $(p=0.03)$. Being widowed $(p=0.04)$ or separated/ divorced $(p=0.03)$, a history of diabetes $(p=0.04)$ or having severe erectile dysfunction $(p=0.003)$ were covariates negatively associated with the 
TABLE 1 Characteristics of the Analysis Cohort $(n=460)$.

\begin{tabular}{|l|c|}
\hline & $\begin{array}{c}\text { Value [mean } \\
\text { (SD) or n (\%)] }\end{array}$ \\
\hline Age (years) & $65.2(9.7)$ \\
\hline Testosterone concentration (nmol/L) & $15.9(5.3)$ \\
\hline CD-I masculinity score & \\
- Total score (max 110) & $82.6(13.6)$ \\
Sub-domain score & $11.4(2.5)$ \\
- Action approach (max 15) & $7.0(2.0)$ \\
- Emotional self-reliance (max 10) & $18.0(4.0)$ \\
- Physical strength (max 25) & $17.1(3.6)$ \\
- Family responsibilities (max 20) & $15.2(3.1)$ \\
- Optimistic capacity (max 20) & $13.9(4.8)$ \\
- Sexuality (max 20) & $100.5(12.3)$ \\
\hline Waist circumference (cm) & \\
\hline Sex-hormone-binding globulin & $37.1(15.2)$ \\
(nmol/L) & $41(9 \%)$ \\
\hline Smoker (\%) & \\
\hline Income & $155(34 \%)$ \\
- Low income - $\$ 440,000$ & $166(36 \%)$ \\
- Middle income - \$40,000-\$80,000 & $139(30 \%)$ \\
- High income - >\$80,000 & \\
\hline Employment & $192(42 \%)$ \\
- Full-time employment & $41(8 \%)$ \\
- Casual employment & $206(45 \%)$ \\
- Retired & $21(5 \%)$ \\
- Other & $111(24 \%)$ \\
\hline Education & $55(12 \%)$ \\
- Did not complete high school & $29(6 \%)$ \\
- Completed high school & $175(38 \%)$ \\
- TAFE/Apprenticeship* & $73(16)$ \\
- Trade certificate or diploma & $17(4 \%)$ \\
- Bachelor + & $38(6 \%)$ \\
- Other & $30(7 \%)$ \\
\hline Marital status & $29(6 \%)$ \\
- Married or with partner & $66(14)$ \\
- Separated/divorced & $45(3 \%)$ \\
- Widowed & $16(3 \%)$ \\
- Never married & \\
\hline History of: & \\
- Prostate cancer & - Anxiety in the past 12 months \\
- Depression in the past 12 months & - Angina \\
- Diabetes & \\
\hline
\end{tabular}

TABLE 1 Continued

\begin{tabular}{l|c|}
\hline & $\begin{array}{c}\text { Value [mean } \\
\text { (SD) or n (\%)] }\end{array}$ \\
\hline Erectile dysfunction & \\
- Nil - mild difficulty & $273(59 \%)$ \\
- Moderate difficulty & $79(17 \%)$ \\
- Severe difficulty & $108(24 \%)$ \\
\hline \\
+ All data collected at time of masculinity questionnaire \\
completion with the exception of waist circumference, \\
sex hormone binding globulin and serum testosterone \\
concentration, which were taken from the FAMAS 2 timepoint \\
due to concurrent lack of data. \\
* TAFE (Technical and Further Education) are vocational \\
courses provided in Australia separate from University for \\
higher learning.
\end{tabular}

physical strength sub-domain score. Not having a partner (widowed $p<0.001$, separated/divorced $p<$ 0.001 , never married $p<0.001$ ) was the only covariate associated, negatively, with the family responsibilities sub-domain score. There was a negative association between the optimistic capacity sub-domain score and age $(p=0.008)$, WC $(p=0.005)$, a history of anxiety $(p<0.001)$ and severe erectile dysfunction $(p<0.001)$. The only factors associated, negatively, with the sexuality sub-domain was WC $(p=0.02)$ and moderate $(p=0.008)$ and severe $(p<$ 0.001 ) erectile dysfunction (Supplementary Table 2).

In the sensitivity analysis, consistent findings of an association between erectile dysfunction and total masculinity score were identified. It was noted that participants who did not answer the question regarding erectile dysfunction had significantly lower masculinity scores compared to those who provided an answer $[-15.2(19.8,-10.40)<0.001]$ (Supplementary Table 4).

\section{Covariates and Serum Testosterone Concentration [ $\beta$, (95\% Confidence Intervals) $p$ Value]}

After adjusting for covariates, the serum testosterone concentration was only positively associated with SHBG $[0.52,(0.45,0.60),<0.001]$, and inversely associated with age $[-0.01,(-0.02,0.005),<0.001]$ and WC $[-0.004,(-0.007,0.002),<0.001]$ (Table 3 ). 


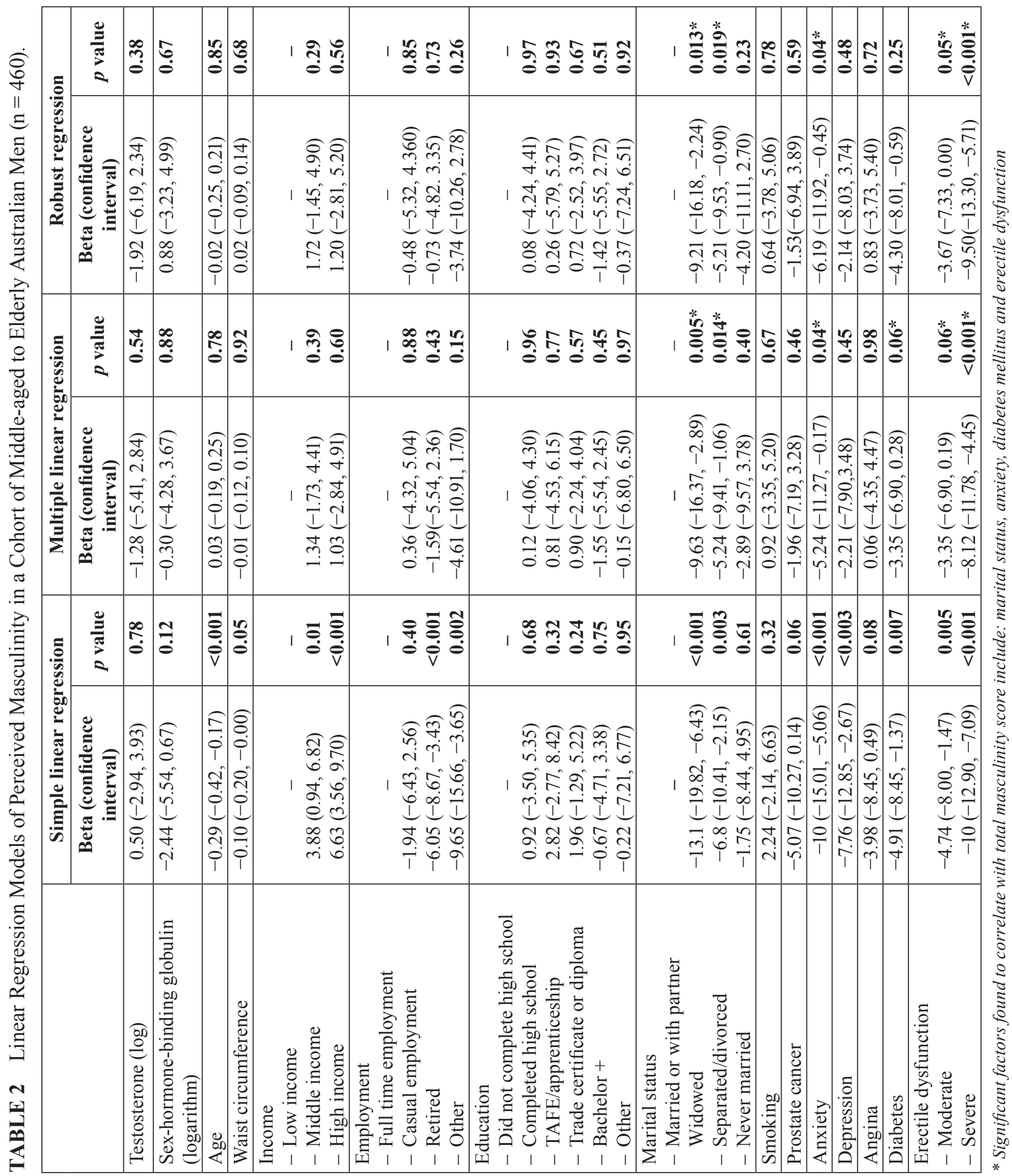

J Mens Health Vol 16(4):e28-e44; 05 October 2020

This article is distributed under the terms of the Creative Commons Attribution-Non Commercial 4.0 International License. (C2020 Andrew Peel et al. 


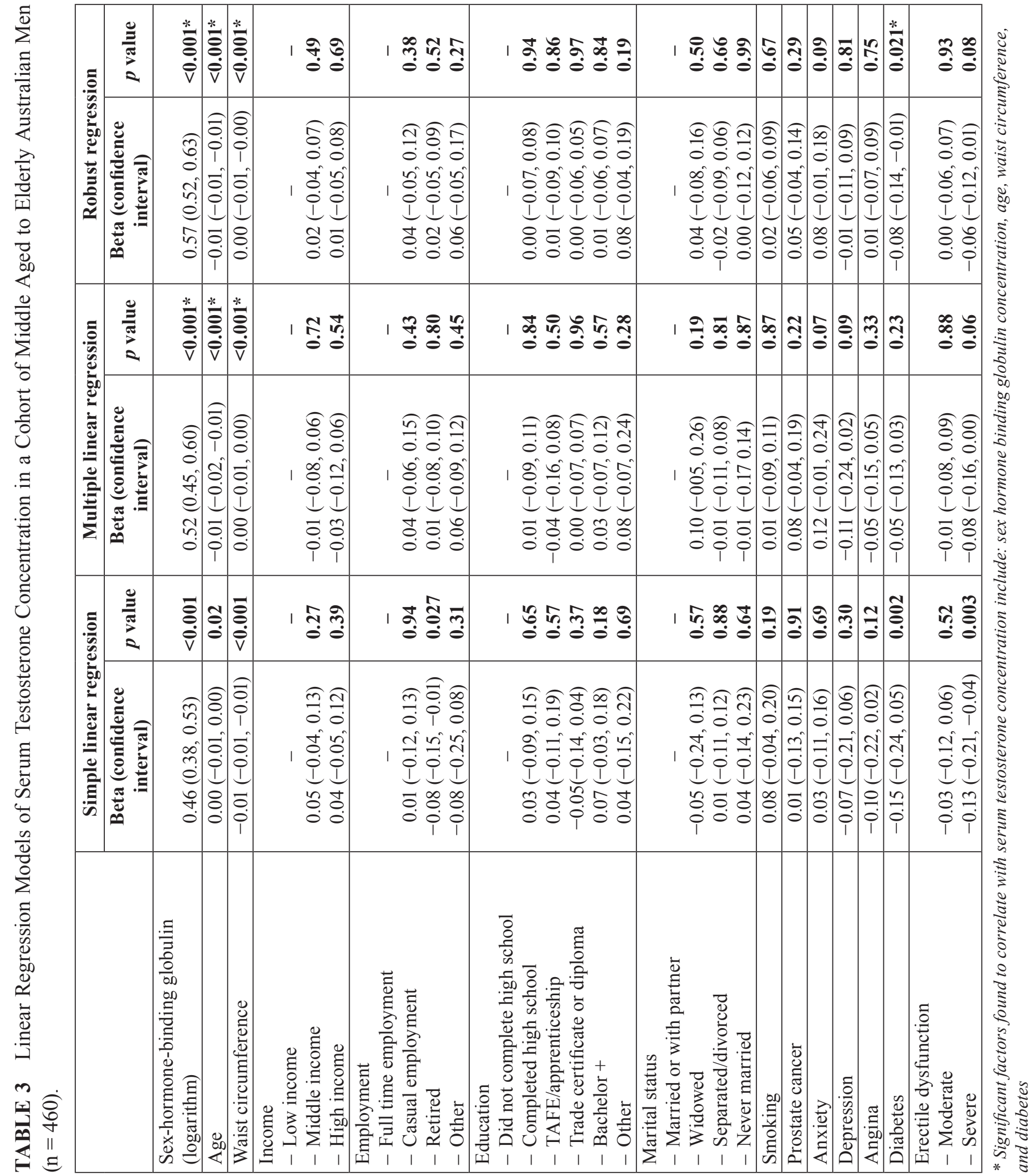

J Mens Health Vol 16(4):e28-e44; 05 October 2020

This article is distributed under the terms of the Creative Commons Attribution-Non Commercial 4.0 International License. (2020 Andrew Peel et al. 
On robust regression, testosterone concentration was also negatively associated with a history of diabetes $[-1.37,(-2.24,-0.50), 0.003]$. History of diabetes is the only covariate variable that was associated with both testosterone concentration and masculinity score.

\section{DISCUSSION}

In this study of middle-aged to older community-dwelling men, serum testosterone was not associated with self-perceived masculinity, as reported by the MCD-I total score or any masculinity subdomain score. The data were instead consistent with the notion that masculinity is most strongly related to physical and psychological health, rather than social constructs. ${ }^{24}$

The primary outcome accords with the only similar study identified assessing men (71 men aged 19-24 years), which also was unable to identify a relationship between salivary testosterone and self-perceived masculinity, as assessed by the Bem Sex-Role Inventory Questionnaire. ${ }^{16}$ The only other study identified ${ }^{15}$ assessed gender roles in females, and is as such deemed not applicable to this study.

The psychological and physical condition factors negatively impacting self-perceived total MCD-1 masculinity score or its sub-domains were moderate or severe erectile dysfunction, anxiety and relationship status. The most significant factor was moderate or severe erectile dysfunction. This accords with a meta-analysis showing a strong relationship between sexual dysfunction and diminished masculinity in men who have been treated for prostate cancer. ${ }^{25}$ In the sensitivity analysis, it was also noted that a lack of response to questions regarding erectile dysfunction was also associated with a significantly reduced masculinity score (15.1 point reduction, compared to 8.2 point reduction for severe erectile dysfunction). The cause for this different is unknown.

Anxiety and mental health disorders have previously been positively associated with "masculine discrepancy," 26 and conformity to specific masculine norms, such as self-reliance or power over women (as determined by the Conformity to Masculine Norms Inventory-94), have been associated with negative mental health outomes. ${ }^{27}$ Our study assessed the relationship between anxiety and self-perceived masculinity, finding consistent results of the two being intrinsically linked, in particular in the optimism domain of the MCD-I questionnaire.

Adherence to traditional masculinity roles has previously been identified as a key component to compliance with diabetes self-care, ${ }^{28,29}$ where generally self-care is not considered a masculine norm. We have been unable to identify any prior studies assessing the impact of diabetes on an individuals' sense of masculinity based on objective questionnaire data. In a qualitative study, it was identified that men either engaged with, or rejected, medical knowledge to regain their competency lost in the diagnosis of an illness. ${ }^{30}$ Taken together, our data relating to chronic disease and masculinity indicate that higher perceived masculinity may be associated with better health status or response to new health status. ${ }^{31-33}$

Self-perceived masculinity has previously been found to be modulated by multiple factors, including age, social class, ethnicity, occupation, geographical location and disability. ${ }^{1,3-7}$ In our study, relationship status was strongly associated with MCD-I masculinity scores. Relationship status was positively influential across multiple domains (physical strength and family responsibility) of self-perceived masculinity, rather than a single component. Only two prior studies regarding masculinity and marital status have been identified in the literature. One study, using the Personal Attributes questionnaire with 87 men and 183 women, identified that the instrumental (masculine) scale was related to marital status, with married men having higher scores, with no similar impact in females. ${ }^{34}$ The second was a qualitative assessment of 19 early male widowers, which identified that the men felt a loss of masculinity as they are thrust into a new role, and attempt to reclaim their masculinity through work or marriage. ${ }^{35}$ 
The major strengths of the current study are: the large well-characterised, longitudinally followed cohort of community-dwelling men; the measurement of serum testosterone in fasted morning samples using triple quadrupole mass spectrometry; and the use of a contextually appropriate and validated instrument to assess self-perceived masculinity in middle-aged to elderly men, including those with chronic health conditions. The concordance with the findings of others using a range of different masculinity assessment tools is reassuring, ${ }^{16,25,26,28,29}$ albeit these studies being not undertaken in a similar cohort of middle-aged to elderly men, and not undertaken with a masculinity questionnaire contextualised for chronic disease.

The major limitation of this study is the temporal difference between when serum testosterone concentrations were measured and when the MCD-I questionnaire was administered. To address this, the multivariable analysis was repeated only using data from participants who had minor changes in the serum testosterone concentration between wave 1 and wave 2 assessments (5 years). The major results in these cohorts were relatively unchanged. The MCD-I was administered at only one time point, and accordingly the cross-sectional nature of the analyses precludes assessment of directionality

This study provides evidence against the perception that physiological testosterone concentrations impact self-perceived masculinity, but rather characteristics of masculinity are abrogated by chronic psychological and physical disorders. The implications of this on disease-related behaviour and health services is currently undetermined, and further investigation into the impact of modification of these factors is required.

\section{REFERENCES}

1. Canham. The interaction of masculinity and control and its impact on the experience of suffering for an older man. J Aging Stud 2009;23(2):90-6. https:// doi.org/10.1016/j.jaging.2008.12.003
2. Chambers SK, Hyde MK, Oliffe JL, et al. Measuring masculinity in the context of chronic disease. Psychol Men Mascul 2016;17(3):228-42. https://doi. org $/ 10.1037 /$ men0000018

3. Kachel S, Steffens M, Niedlick C. Traditional masculinity and femininity: Validation of a new scale assessing gender roles. Front Psychol 2016;7:956. https://doi.org/10.3389/fpsyg.2016.00956

4. ConnellR,MesserschmidtJ.Hegemonic masculinity: Rethinking the concept. Gender Soc 2005;19(5):82959. https://doi.org/10.1177/0891243205278639

5. Tannenbaum C, Frank B. Masculinity and health in late life men. Am J Mens Health 2011;5(3):243-54. https://doi.org/10.1177/1557988310384609

6. Stergiou-Kita M, Mansfield E, Calantonio A, Moody J, Mantis S. What's gender got to do with it? Examining masculinities, health and safety and return to work in male dominated skilled trades. Work 2016;54(3):721-33. https://doi.org/10.3233/ WOR-162322

7. Stergiou-Kita M, Mansfield E, Bezo R, et al. Danger zone: Men, masculinity and occupational health and safety in high risk occupations. Saf Sci 2015;1(80): 213-20. https://doi.org/10.1016/j.ssci.2015.07.029

8. Snyder P, Bhasin S, Cunninghma G, et al. Effects of testosterone treatment in older men. $\mathrm{N}$ Engl $\mathrm{J}$ Med 2016;374(7):611-24. https://doi.org/10.1056/ NEJMoa1506119

9. Hackett G, Cole N, Bhartia M, Kennedy D, Raju J, Wilkinson P. Testosterone replacement therapy with long acting testosterone undecanoate improves sexual function and quality of life parameters vs. placebo in a population of men with type 2 diabetes. J Sex Med 2013;10:1612-17. https://doi.org/10.1111/jsm.12146

10. Welling L, Moreua B, Bird B, Hansend S, Carré JM. Exogenous testosterone increases men's perception of their own physical dominance. Psychoneuroendocrinology 2016;64:136-42. https:// doi.org/10.1016/j.psyneuen.2015.11.016

11. Carre J, Geniole S, Ortiz T, Bird BM, Videto A, Bonin PL. Exogenous testosterone rapidly increases aggressive behaviour in dominant and impulsive men. Biol Psychiatry 2016;82(4):249-56. https://doi. org/10.1016/j.biopsych.2016.06.009

12. Bhasin S, Storer T, Berman N, et al. The effects of supraphysiologic doses of testosterone on muscle

J Mens Health Vol 16(4):e28-e44; 05 October 2020

This article is distributed under the terms of the Creative Commons Attribution-Non Commercial 4.0 International License. (C2020 Andrew Peel et al. 
size and strength in normal men. $\mathrm{N}$ Engl $\mathrm{J}$ Med 1996;335(1):1-7. https://doi.org/10.1056/NEJM1996 07043350101

13. Dudek P, Kozakowski J, Zgliczynski W. Late onset hypogonadism. Menopause Rev 2017;16(2):66-9. https://doi.org/10.5114/pm.2017.68595

14. Surampudi P, Swerdloff R, Wang C. An update on male hypogonadism therapy. Expert Opin Pharmacother 2014;15(9):1247-64. https://doi.org/1 0.1517/14656566.2014.913022

15. Baucom DH, Besch PK, Callaham S. Relationship between testosterone concentration, sex role identity and personality among females. J Personal Soc Psychol 1985;48(5):1218-26. https://doi.org/10.1037/ 0022-3514.48.5.1218

16. McIntyre M, Li A, Chapman J, Lipson SF, Ellison PT. Social status, masculinity and testosterone in young men. Pers Individ Diff 2011;51:392-6. https://doi.org/10.1016/j.paid.2010.03.015

17. Shi Z, Araujo AB, Martin S, O'Loughlin P, Wittert GA. Longitudinal changes in testosterone over 5 years in community dwelling men. J Clin Endocrinol Metab 2013;98(8):3289-97. https://doi. org/10.1210/jc.2012-3842

18. Camacho EM, Huhtaniemi IT, O'Neill TW, et al. Age-associated changes in hypothalamic-pituitarytesticular function in middle-aged and older men are modified by weight change and lifestyle factors: Longitudinal results from the European Male Ageing Study. Eur J Endocrinol 2013;168(3):44555. https://doi.org/10.1530/EJE-12-0890

19. Carver L, Vafaei A, Guerra R, Freire A, Phillips SP. Gender differences: Examination of the 12-item Bem Sex Role inventory (BSRI-12) in an older Brazilian population. PLoS One 2013;8(10):e766356. https://doi.org/10.1371/journal.pone.0076356

20. Ahmed T, Vafaei A, Belanger E, Phillips SP, Zunzunegui M-V. Bem Sex Role Inventory validation in the international mobility in aging Angelier study. Can J Aging 2016;35(3):348-60. https://doi. org/10.1017/S0714980816000404

21. Thompson EH, Bennett KM. Measurement of masculinity ideologies: A (critical) review. Psychol Men Mascul 2015;9:1-4. https://doi.org/10.1037/a0038609

22. Occhipinti S, Laurie K, Hyde M, et al. Measuring masculinity in men with chronic disease. Am J
Mens Health 2019;13(4):1557988319859706. https:// doi.org/10.1177/1557988319859706

23. Martin SA, Appleton SL, Vakulin A, et al. The association of obstructive sleep apnoea and nocturnal hypoxaemia with the development of abnormal HbA1c in a population cohort of men without diabetes. Diab Res Clin Pract 2006;114:151-159. https:// doi.org/10.1016/j.diabres.2015.12.007

24. Tsang VWL, Skead C, Wassersug RJ, PalmerHague JL. Impact of prostate cancer treatments on men's understanding of their masculinity. Psychol Men Mascul 2019;20(2):214-225. https://doi. org/10.1037/men0000184

25. Chambers SK, Chung E, Wittert G, Hyde MK. Erectile dysfunction, masculinity, and psychosocial outcomes: A review of the experiences of men after prostate cancer treatment. Transl Androl Urol 2017;6(1):60-8. https://doi.org/10.21037/tau.2016.08.12

26. Yang X, Lau JTF, Wang Z. The mediation roles of discrepancy stress and self-esteem between masculine role discrepancy and mental health problems. J Affect Disord 2018;1(235):513-20. https://doi. org/10.1016/j.jad.2018.04.085

27. Wong YJ, Ho MR, Wang, SY. Meta-analyses of the relationship between conformity to masculine norms and mental health-related outcomes. J Counsel Psychol 2017;64(1):80-93. https://doi.org/10.1037/cou0000176

28. Jack L, Toston T, Jack NH, Sims M. A gender centered ecological framework targeting Black men living with diabetes: Integrating a "masculinity" perspective in diabetes management and education research. Am J Mens Health 2010;4(1):7-15. https:// doi.org/10.1177/1557988308321956

29. Liburd LC, Namageyo-Funa A, Jack L. Understanding "masculinity" and the challenges of management type 2 diabetes among African American men. J Natl Med Assoc 2007;99(5):550-2.

30. Dale C, Angus J, Nielson L, et al. "I'm no superman": Understanding diabetic men, masculinity and cardiac rehabilitation. Qual Health Res 2015;25(12): 1648-61. https://doi.org/10.1177/1049732314566323

31. Rochelle T. Cross cultural differences in the relationship between conformity to masculine norms and health behaviour among men in Hong Kong. Br J Health Psychol 2019;24:159-74. https://doi. org/10.1111/bjhp.12345 
32. Gerdes Z, Levant R. Complex relationships among masculine norms and health/well-being outcomes: Correlation patterns of the conformity to masculine norms inventory subscales. Am J Mens Health 2018;12(2):229-40. https://doi.org/10.1177/ 1557988317745910

33. Ulloa J, Sun C, Rhodes S. The intersection between masculinity and health among rural immigrant Latino men. Int J Mens Health 2017;16(1):84-95.
34. Macdonald N, Ebert P. Marital status and age as related to masculine and feminine personality dimensions and self esteem. J Soc Psychol 2000;127(3):289-98. https://doi.org/10.1080/002245 45.1987.9713694

35. Bandini J, Thompson E. "Widowerhood": Masculinities and spousal loss in the late 1960s. OMEGA 2013;68(2):123-41. https://doi.org/10.2190/OM.68.2.c 
SUPPLEMENTARY TABLE 1 Comparison between Analytic Cohort and Those Not Meeting the Inclusion Criteria (at time of Recruitment - FAMAS 1).

\begin{tabular}{|c|c|c|c|c|}
\hline & & $\begin{array}{c}\text { Excluded cohort } \\
\quad(n=735)\end{array}$ & $\begin{array}{c}\text { Analysis cohort } \\
(n=460)\end{array}$ & $p$ value \\
\hline \multicolumn{2}{|l|}{ Age - years (mean) } & 56.4 & 52.9 & $<0.001$ \\
\hline \multicolumn{2}{|c|}{ Serum testosterone concentration $-\mathrm{nmol} / \mathrm{L}$ (mean) } & 16.24 & 17.15 & 0.34 \\
\hline \multicolumn{2}{|c|}{ Waist circumference $-\mathrm{cm}$ (mean) } & 100.7 & 100.8 & 0.92 \\
\hline Smoking & Yes & $182(25 \%)$ & $87(19 \%)$ & 0.02 \\
\hline Marital status & $\begin{array}{l}\text { Married/living with partner } \\
\text { Separated/divorced } \\
\text { Widowed } \\
\text { Never married } \\
\text { Did not complete }\end{array}$ & $\begin{array}{c}576(78 \%) \\
91(12 \%) \\
25(3 \%) \\
41(6 \%) \\
2(0 \%) \\
\end{array}$ & $\begin{array}{c}398(86 \%) \\
35(8 \%) \\
8(2 \%) \\
19(4 \%) \\
0(0 \%) \\
\end{array}$ & 0.008 \\
\hline Diabetes & Yes & $143(19 \%)$ & $57(12 \%)$ & 0.002 \\
\hline Depression & Yes & $95(13 \%)$ & $54(12 \%)$ & 0.61 \\
\hline Anxiety & Yes & $68(9 \%)$ & $43(9 \%)$ & 1 \\
\hline Education & $\begin{array}{l}\text { Trade/apprenticeship } \\
\text { Certificate/Diploma } \\
\text { Bachelor's degree or higher } \\
\text { Don't know } \\
\text { Did not complete }\end{array}$ & $\begin{array}{c}254(35 \%) \\
178(24 \%) \\
76(10 \%) \\
9(1 \%) \\
218(30 \%)\end{array}$ & $\begin{aligned} 143(31 \%) \\
125(27 \%) \\
69(15 \%) \\
5(1 \%) \\
118(26 \%) \\
\end{aligned}$ & 0.07 \\
\hline Income & $\begin{array}{l}<\$ 40,000 \\
40,001-\$ 80,000 \\
>\$ 80,000 \\
\text { Did not complete }\end{array}$ & $\begin{array}{c}383(52 \%) \\
229(31) \\
106(14 \%) \\
17(2 \%) \\
\end{array}$ & $\begin{array}{c}159(35 \%) \\
208(45 \%) \\
89(19 \%) \\
4(1 \%) \\
\end{array}$ & $<0.001$ \\
\hline Employment & $\begin{array}{l}\text { Full-time work } \\
\text { Part-time work } \\
\text { Unemployed } \\
\text { Retired } \\
\text { Other } \\
\text { Did not complete }\end{array}$ & $\begin{array}{c}218(30 \%) \\
69(9 \%) \\
23(3 \%) \\
257(35 \%) \\
67(9 \%) \\
1(0 \%) \\
\end{array}$ & $\begin{array}{c}279(60 \%) \\
44(10 \%) \\
9(2 \%) \\
93(20 \%) \\
35(8 \%) \\
0(0.00 \%)\end{array}$ & $<0.001$ \\
\hline Angina & Yes & $55(7 \%)$ & $23(5 \%)$ & 0.12 \\
\hline Erectile dysfunction & $\begin{array}{l}\text { Did not answer } \\
\text { Mild } \\
\text { Moderate } \\
\text { Severe }\end{array}$ & $\begin{array}{c}16(2 \%) \\
472(64 \%) \\
35(5 \%) \\
212(29 \%)\end{array}$ & $\begin{array}{c}4(1 \%) \\
359(78 \%) \\
12(3 \%) \\
85(18 \%)\end{array}$ & $<0.001$ \\
\hline Prostate cancer & Yes & $29(3.95 \%)$ & $4(1 \%)$ & 0.002 \\
\hline
\end{tabular}

J Mens Health Vol 16(4):e28-e44; 05 October 2020

This article is distributed under the terms of the Creative Commons Attribution-Non

Commercial 4.0 International License. (C2020 Andrew Peel et al. 
Testosterone and self-perceived masculinity

\begin{tabular}{|c|c|c|c|c|c|c|c|c|c|c|c|c|c|c|c|}
\hline$=$ & \begin{tabular}{|l|}
$\vec{\alpha}$ \\
$\dot{o}$
\end{tabular} & के & 离 & | & $\stackrel{\pi}{\pi}$ & 导葛 & 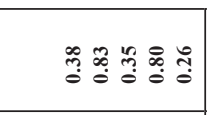 & $\begin{array}{ll}9 \\
\end{array}$ & $\stackrel{n}{i n}$ & $\stackrel{\infty}{0}$ & $\hat{a}$ & 㐌 & : & 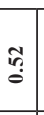 & \\
\hline 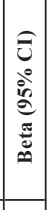 & 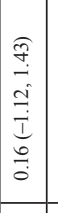 & 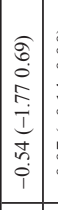 & \begin{tabular}{|c|} 
\\
0 \\
0 \\
$\dot{j}$ \\
$\dot{1}$ \\
$\vdots$ \\
0 \\
$\dot{i}$ \\
\end{tabular} & \begin{tabular}{|c|}
0 \\
0 \\
0 \\
0 \\
0 \\
0 \\
0 \\
0 \\
0 \\
0 \\
\end{tabular} & 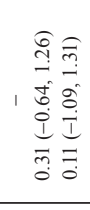 & 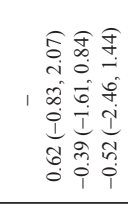 & 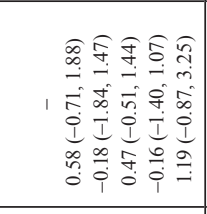 & 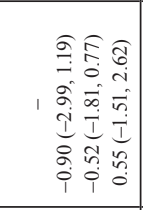 & 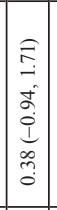 & 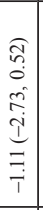 & 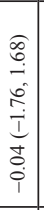 & 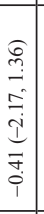 & 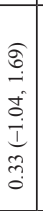 & 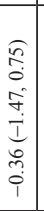 & \\
\hline$=$ & 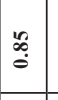 & 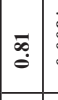 & \begin{tabular}{|c|c}
0 \\
0 \\
0 \\
0 \\
0
\end{tabular} & \begin{tabular}{|c|}
0 \\
0 \\
0 \\
$\vdots$ \\
0
\end{tabular} & 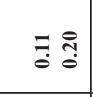 & 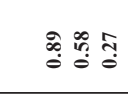 & 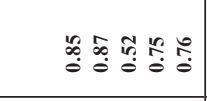 & 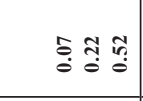 & 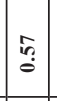 & $\begin{array}{c}\stackrel{a}{a} \\
\dot{\infty}\end{array}$ & | & $\stackrel{\check{\Xi}}{\Xi}$ & $\begin{array}{c}+\overrightarrow{0} \\
\stackrel{\circ}{\circ}\end{array}$ & $\stackrel{\substack{0 \\
:}}{\stackrel{0}{0}}$ & \\
\hline 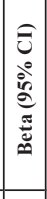 & 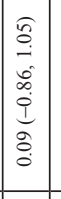 & 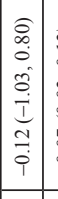 & 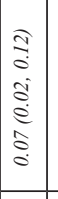 & $\mid$\begin{tabular}{c|}
0 \\
0 \\
0 \\
0 \\
0 \\
0 \\
0 \\
0 \\
0
\end{tabular} & 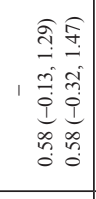 & 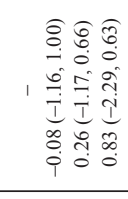 & 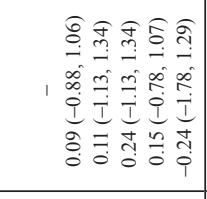 & 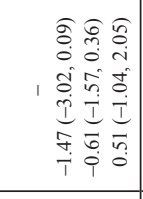 & 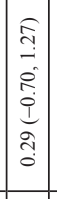 & 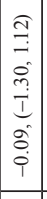 & 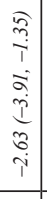 & 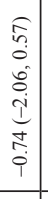 & 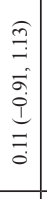 & 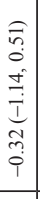 & \\
\hline$=$ & $\because$ & $\stackrel{s}{s}$ & $\mid \begin{array}{l}n \\
:\end{array}$ & $\mid$\begin{tabular}{c}
$\infty$ \\
$\substack{\infty \\
\hdashline}$ \\
0
\end{tabular} & 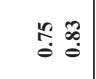 & $\begin{array}{ll}\bar{n} \\
=\end{array}$ & $\Phi$ & 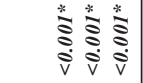 & 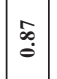 & $\stackrel{f}{\circ}$ & $\stackrel{\square}{\circ}$ & $\stackrel{\infty}{\circ}$ & $\stackrel{\infty}{\circ}$ & $\stackrel{m}{3}$ & \\
\hline 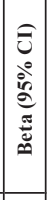 & 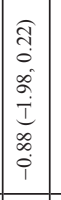 & \begin{tabular}{|c|c|}
$\widehat{r}$ & \\
0 \\
0 \\
0 \\
0 \\
0 \\
0 \\
0 \\
0 \\
\end{tabular} & \begin{tabular}{|c|}
0 \\
0 \\
0 \\
$i$ \\
0 \\
0 \\
$i$ \\
0 \\
0 \\
$\dot{i}$ \\
\end{tabular} & 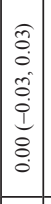 & 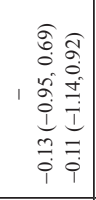 & 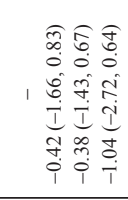 & 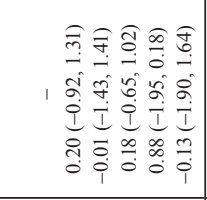 & 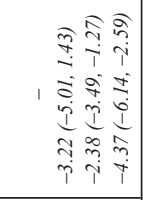 & 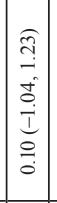 & 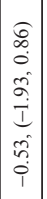 & 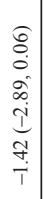 & 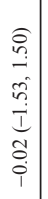 & 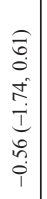 & 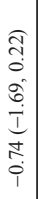 & \\
\hline$\approx$ & 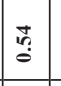 & $\begin{array}{l}\stackrel{\vec{b}}{\circ} \\
\end{array}$ & \begin{tabular}{|l|}
$\stackrel{\infty}{\infty}$ \\
$\stackrel{\infty}{\circ}$ \\
\end{tabular} & \begin{tabular}{|l|l}
0 \\
0 \\
0 \\
0
\end{tabular} & 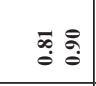 & ? & 80 & $\begin{array}{ll}4 \\
0 \\
0 \\
0\end{array}$ & : & 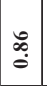 & ga & $\stackrel{n}{=}$ & $\stackrel{2}{:}$ & 䇏 & \\
\hline 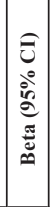 & 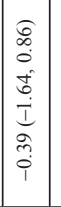 & 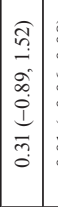 & $\mid$\begin{tabular}{|c|}
0 \\
0 \\
0 \\
0 \\
0 \\
0 \\
$i$ \\
0 \\
0 \\
0 \\
0
\end{tabular} & $\mid \begin{array}{l}0 \\
0 \\
0 \\
0 \\
0 \\
0 \\
0 \\
0 \\
0 \\
i \\
1\end{array}$ & 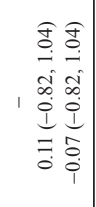 & 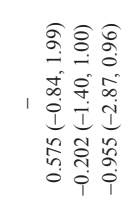 & 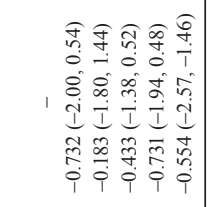 & 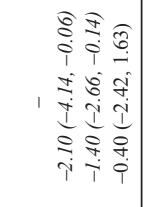 & 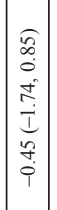 & 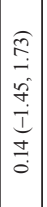 & 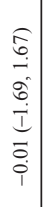 & 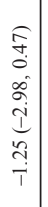 & 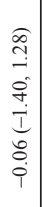 & 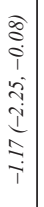 & \\
\hline$=$ & 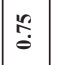 & $\tilde{\tilde{Z}}$ & $\stackrel{\leftrightarrow}{\circ}$ & $\stackrel{?}{\mathscr{8}}$ & 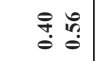 & 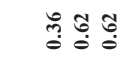 & $\therefore$ & 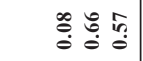 & 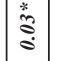 & $\stackrel{\tilde{z}}{3}$ & בั & $\overrightarrow{\underline{b}}$ & $\underset{\delta}{\vec{S}}$ & : & \\
\hline 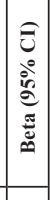 & $\mid$\begin{tabular}{|c|}
0 \\
0 \\
0 \\
0 \\
0 \\
0 \\
0 \\
$\frac{1}{0}$ \\
0 \\
0
\end{tabular} & 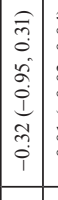 & 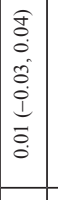 & $\mid$\begin{tabular}{|c|}
0 \\
0 \\
0 \\
$\hat{i}$ \\
0 \\
$i$ \\
0 \\
$i$ \\
$i$
\end{tabular} & 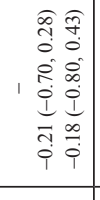 & 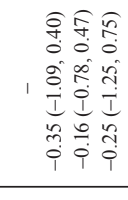 & 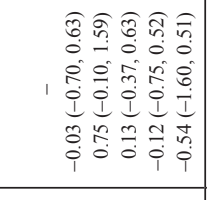 & 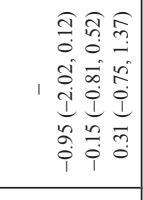 & $\mid$\begin{tabular}{c|}
0 \\
0 \\
$\stackrel{0}{0}$ \\
0 \\
0 \\
0 \\
0 \\
0
\end{tabular} & 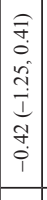 & 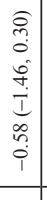 & 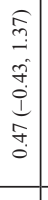 & 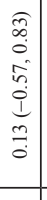 & 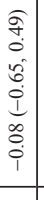 & \\
\hline$=$ & 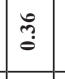 & $\stackrel{R}{a}$ & $\tilde{g}$ & $\stackrel{0}{0}$ & 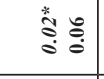 & ถิ ถิ & ลี ถี & $\stackrel{7}{\circ} \stackrel{0}{\circ} \stackrel{7}{\circ}$ & $\stackrel{\check{\varrho}}{\leftrightarrows}$ & $\tilde{\Xi}$ & 总 & 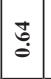 & $\stackrel{\infty}{=}$ & 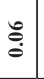 & \\
\hline 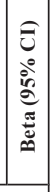 & 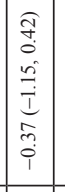 & 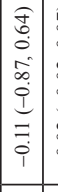 & 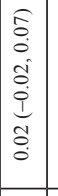 & $\mid \begin{array}{l}0 \\
0 \\
0 \\
0 \\
0 \\
0 \\
0 \\
0 \\
0 \\
0\end{array}$ & 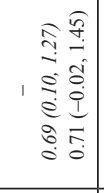 & 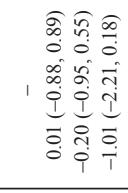 & 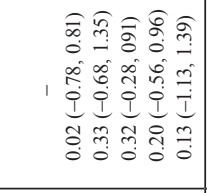 & 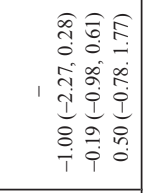 & 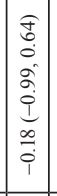 & 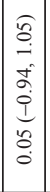 & 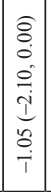 & 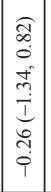 & $\mid$\begin{tabular}{l}
0 \\
0 \\
0 \\
0 \\
$i$ \\
0 \\
$i$ \\
\hdashline \\
0 \\
0
\end{tabular} & 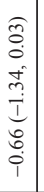 & \\
\hline$\underline{\underline{z}}$ & 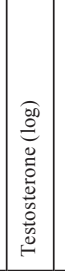 & \begin{tabular}{|c|} 
\\
0 \\
$m$ \\
$m$ \\
$m$
\end{tabular} \mid & & 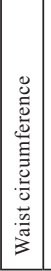 & क्ष & & 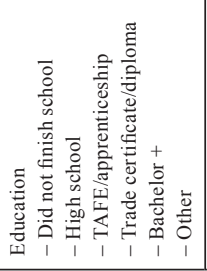 & 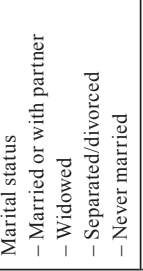 & $\left.\right|^{\infty}$ & & & & & & \\
\hline
\end{tabular}

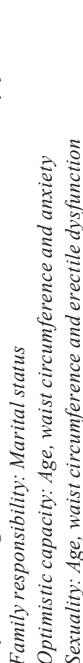

J Mens Health Vol 16(4):e28-e44; 05 October 2020

This article is distributed under the terms of the Creative Commons Attribution-Non Commercial 4.0 International License. (C2020 Andrew Peel et al. 
SUPPLEMENTARY TABLE 3 Cohort Characteristics and Linear Regression Model of Masculinity Total Component of MCDI Questionnaire in a Cohort of Middle-aged to Elderly Australian Men with Limited Variation in Serum Testosterone Concentration $(n=373)$.

\begin{tabular}{|c|c|c|c|}
\hline & \multirow{2}{*}{$\begin{array}{c}\text { Cohort characteristics } \\
\text { Value [mean (SD) } \\
\text { or } n(\%)] \\
\end{array}$} & \multicolumn{2}{|c|}{ Multiple linear regression } \\
\hline & & $\begin{array}{c}\text { Beta }(95 \% \\
\text { confidence interval) }\end{array}$ & $p$ value \\
\hline Masculinity score & $82.13(13.68)$ & \multicolumn{2}{|l|}{-} \\
\hline Testosterone (logarithm) & $15.91(5.00)$ & $-2.94(-9.11,3.23)$ & 0.35 \\
\hline Sex-hormone-binding globulin (logarithm) & $37.03(15.83)$ & $1.10(-3.88,6.07)$ & 0.66 \\
\hline Age & $65.36(9.76)$ & $0.01(-0.24,0.26)$ & 0.94 \\
\hline Waist circumference & $99.98(12.28)$ & $0.01(-0.12,0.13)$ & 0.94 \\
\hline $\begin{array}{l}\text { Income } \\
\text { - Low income } \\
\text { - Middle income } \\
\text { - High income } \\
\end{array}$ & $\begin{array}{r}134(36 \%) \\
133(36 \%) \\
106(28 \%) \\
\end{array}$ & $\begin{array}{c}- \\
0.65(-2.80,4.11) \\
0.20(-4.19,4.60) \\
\end{array}$ & $\begin{array}{l}0.71 \\
0.93\end{array}$ \\
\hline $\begin{array}{l}\text { Employment } \\
\text { - Full-time employment } \\
\text { - Casual employment } \\
\text { - Retired } \\
\text { - Other }\end{array}$ & $\begin{array}{c}148(40 \%) \\
35(9 \%) \\
173(46 \%) \\
17(5 \%) \\
\end{array}$ & $\begin{array}{c}- \\
0.44(-4.76,5.64) \\
-0.85(-5.34,3.64) \\
-3.47(-10.62,3.69) \\
\end{array}$ & $\begin{array}{l}0.87 \\
0.71 \\
0.34\end{array}$ \\
\hline $\begin{array}{l}\text { Education } \\
\text { - Did not complete high school } \\
\text { - Completed high school } \\
\text { - TAFE/apprenticeship } \\
\text { - Trade certificate or diploma } \\
\text { - Bachelor + } \\
\text { - Other }\end{array}$ & $\begin{array}{c}88(24 \%) \\
48(13 \%) \\
24(6 \%) \\
140(38 \%) \\
57(15 \%) \\
16(4 \%) \\
\end{array}$ & $\begin{array}{r}- \\
1.47(-3.19,6.13) \\
1.49(-4.53,7.50) \\
1.23(-2.36,4.82) \\
-0.14(-4.79,4.50) \\
0.48(-6.61,7.56) \\
\end{array}$ & $\begin{array}{l}0.54 \\
0.63 \\
0.50 \\
0.95 \\
0.90\end{array}$ \\
\hline $\begin{array}{l}\text { Marital status } \\
\text { - Married or with partner } \\
\text { - Widowed } \\
\text { - Separated/divorced } \\
\text { - Never married }\end{array}$ & $\begin{array}{c}312(84 \%) \\
36(10 \%) \\
11(3 \%) \\
14(4 \%) \\
\end{array}$ & $\begin{array}{c}- \\
-12.70(-20.99,-4.41) \\
-6.30(-11.04,-1.56) \\
-2.19(-9.57,5.18)\end{array}$ & $\begin{array}{l}0.003^{*} \\
0.009 * \\
0.56\end{array}$ \\
\hline Smoking & $36(10 \%)$ & $1.42(-3.26,6.10)$ & 0.55 \\
\hline Prostate cancer & $24(6 \%)$ & $-2.64(-8.42,3.14)$ & 0.37 \\
\hline Anxiety & $26(7 \%)$ & $-3.94(-9.94,2.06)$ & 0.20 \\
\hline Depression & $24(6 \%)$ & $-1.88(-8.21,4.44)$ & 0.56 \\
\hline Angina & $29(8 \%)$ & $-1.00(-6.19,4.20)$ & 0.71 \\
\hline Diabetes & $54(14 \%)$ & $-3.10(-7.19,0.98)$ & 0.14 \\
\hline $\begin{array}{l}\text { Erectile dysfunction } \\
\text { - Nil-mild } \\
\text { - Moderate } \\
\text { - Severe }\end{array}$ & $\begin{array}{r}227(61 \%) \\
61(16 \%) \\
85(23 \%)\end{array}$ & $\begin{array}{c}- \\
-4.83(-8.98,-0.68) \\
-8.11(-12.34,-3.88)\end{array}$ & $\begin{array}{r}0.023 * \\
<0.001 *\end{array}$ \\
\hline
\end{tabular}

* Significant factors found to correlate with total masculinity score in the subjects with limited changes in serum testosterone concentration include marital status and erectile dysfunction 


\begin{tabular}{|c|c|c|c|c|c|c|c|c|c|c|}
\hline$\tilde{z}$ & 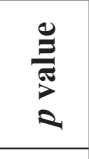 & $\begin{array}{c}\not{a} \\
\dot{\theta} \\
\dot{\theta}\end{array}$ & $\stackrel{f}{f}$ & $\mid \begin{array}{l}5 \\
0 \\
0\end{array}$ & : & $\stackrel{m}{s} \bar{s}$ & 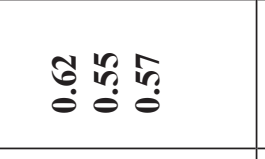 & 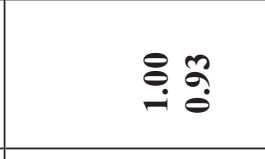 & 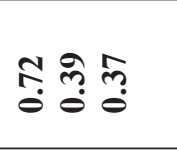 & 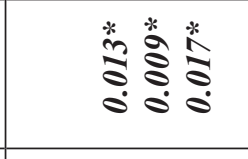 \\
\hline & 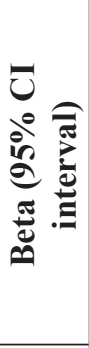 & 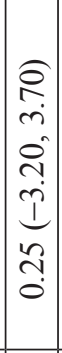 & 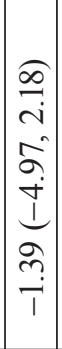 & $\mid \begin{array}{c}0 \\
0 \\
0 \\
0 \\
i \\
0 \\
1 \\
n \\
0 \\
0 \\
1\end{array}$ & $\begin{array}{c}0 \\
0 \\
0 \\
0 \\
0 \\
0 \\
1 \\
m \\
0 \\
0\end{array}$ & 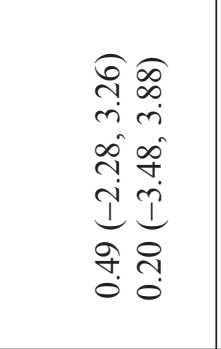 & 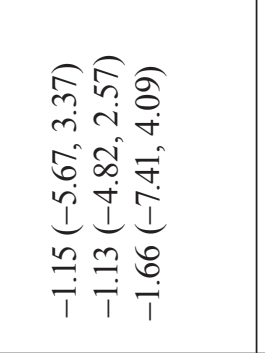 & 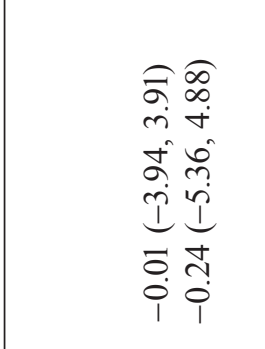 & 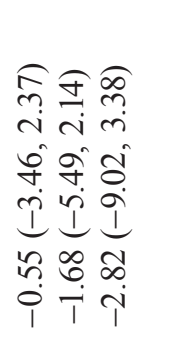 & 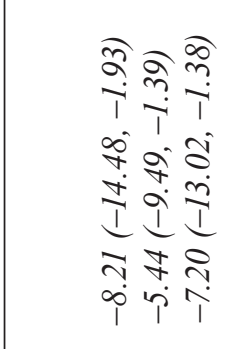 \\
\hline 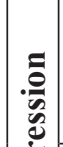 & $\begin{array}{l}\stackrel{\mathscr{E}}{\pi} \\
\frac{\pi}{2} \\
2\end{array}$ & 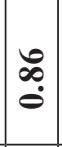 & 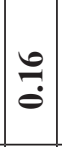 & $\bar{g}$ & o̊ & 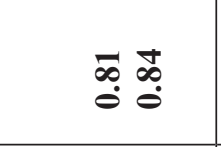 & 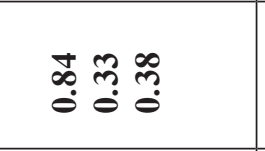 & 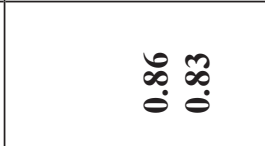 & $\stackrel{0}{0}$ & 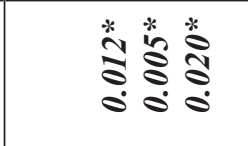 \\
\hline 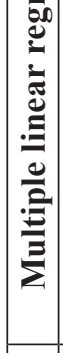 & 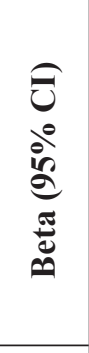 & 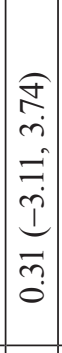 & 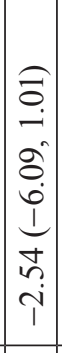 & 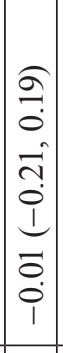 & $\begin{array}{c}0 \\
0 \\
0 \\
0 \\
0 \\
0 \\
1 \\
0 \\
0 \\
0\end{array}$ & 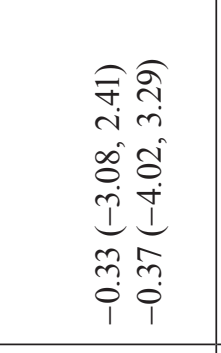 & 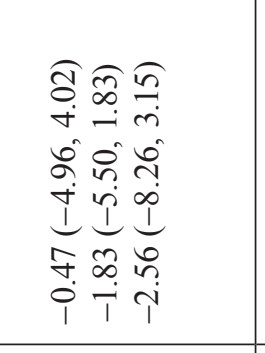 & 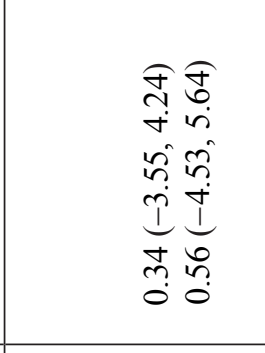 & 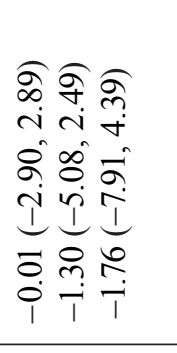 & 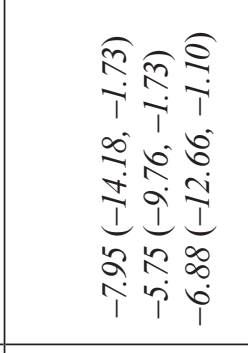 \\
\hline 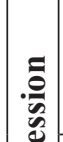 & 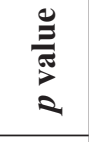 & $\stackrel{f}{q}$ & 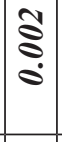 & 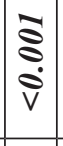 & $\stackrel{5}{\circ}$ & 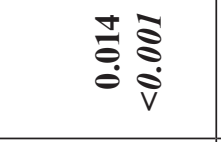 & 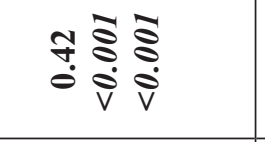 & $\stackrel{p}{\stackrel{0}{g}} \stackrel{0}{=}$ & 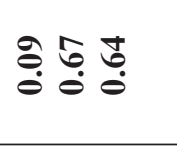 & \begin{tabular}{l}
5 \\
$\vdots$ \\
$\vdots$ \\
\hdashline
\end{tabular} \\
\hline 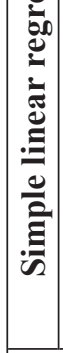 & 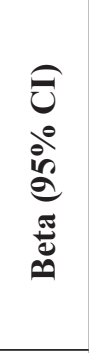 & 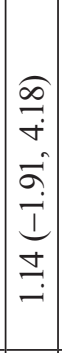 & 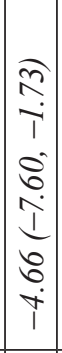 & 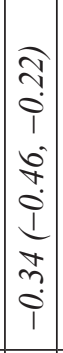 & $\begin{array}{c}\widehat{T} \\
\hat{\delta} \\
0 \\
0 \\
0 \\
0 \\
1 \\
0 \\
0 \\
1 \\
\end{array}$ & 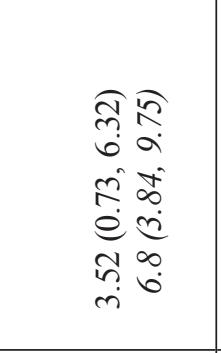 & 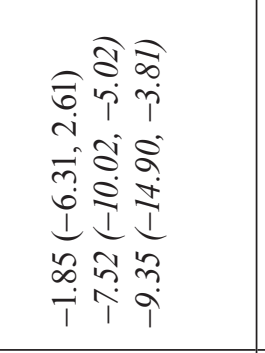 & 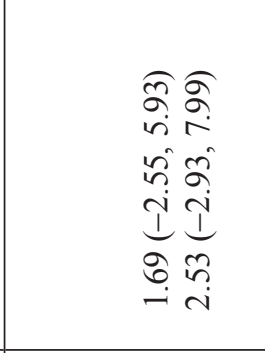 & 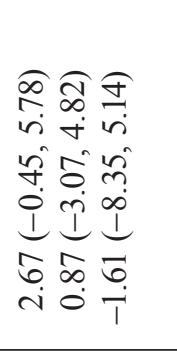 & 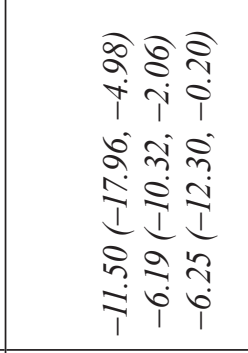 \\
\hline & 递 & 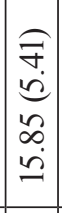 & \begin{tabular}{|c|}
0 \\
$\dot{0}$ \\
$\dot{0}$ \\
$a$ \\
$\dot{2}$ \\
$\dot{m}$ \\
\end{tabular} & 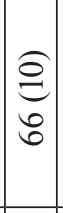 & 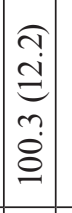 & 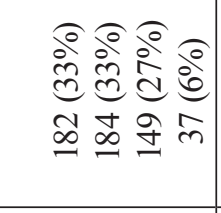 & 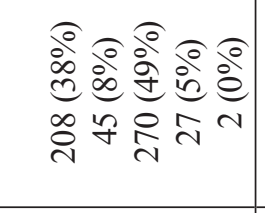 & 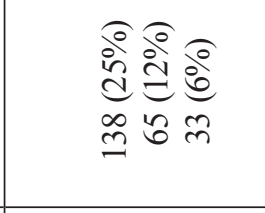 & 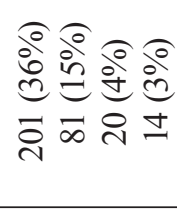 & 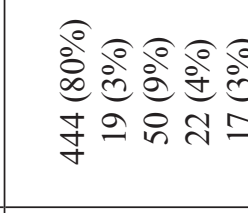 \\
\hline & & 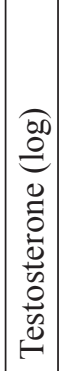 & & & 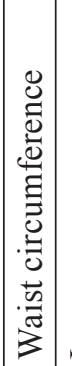 & 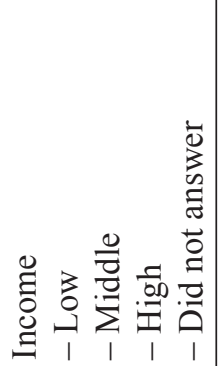 & 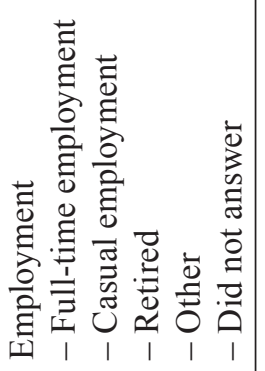 & 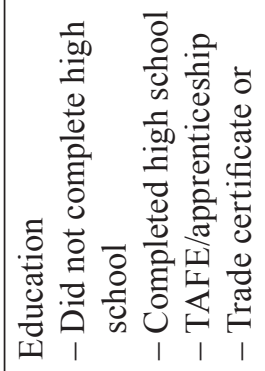 & 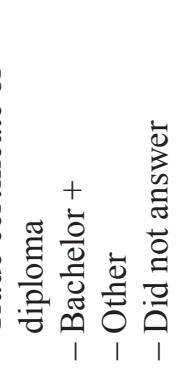 & 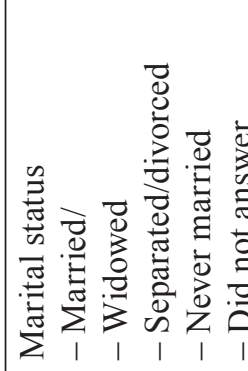 \\
\hline
\end{tabular}

J Mens Health Vol 16(4):e28-e44; 05 October 2020

This article is distributed under the terms of the Creative Commons Attribution-Non Commercial 4.0 International License. (C2020 Andrew Peel et al. 


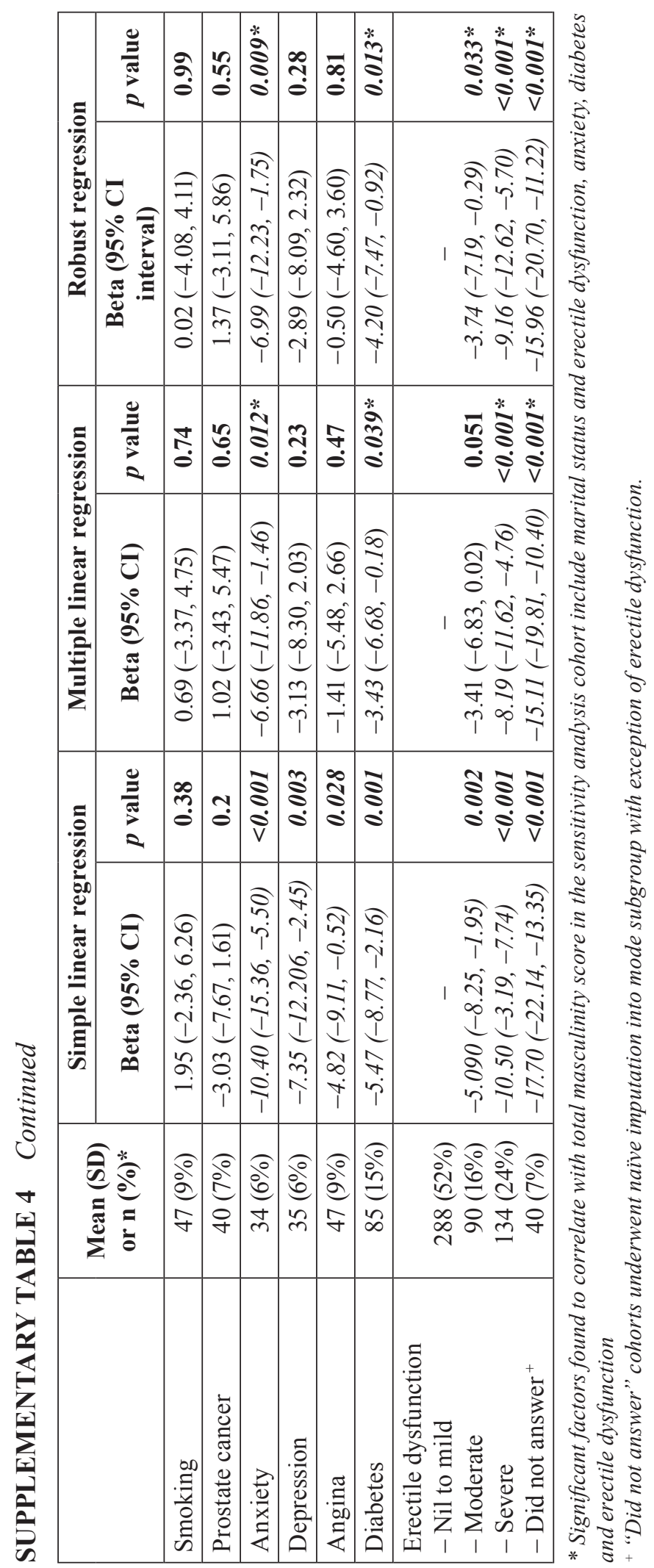

J Mens Health Vol 16(4):e28-e44; 05 October 2020

This article is distributed under the terms of the Creative Commons Attribution-Non Commercial 4.0 International License. (C2020 Andrew Peel et al. 